\title{
EUTOMIA
}

Revista de Literatura e Linguística

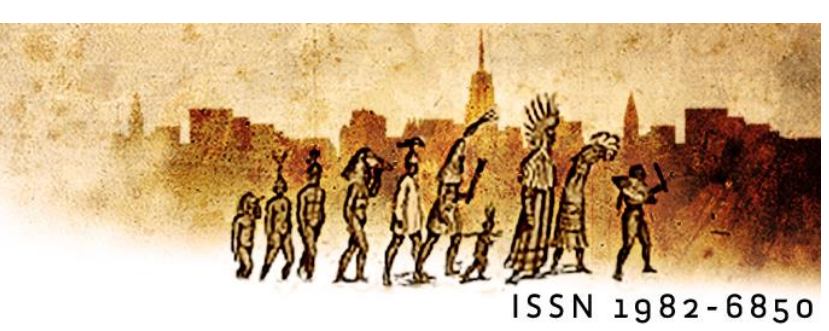

\section{A ética e a educação como processo da formação humana}

\section{Ethics and education as a process of human formation}

\author{
Martinho Gilson Cardoso Chingulo -(UEL) ${ }^{i}$ \\ Adrielen Amancio da Silva -(UEL) \\ Adriana Regina de Jesus -(UEL) $)^{i i i}$
}

Resumo: Objetiva-se no presente texto discutir a importância da educação e da ética como elementos fundamentais para formação humana. Partimos do pressuposto de que a educação não é um simples exercício de transmissão de informações ou conteúdo, mas um processo de formação que deve considerar a integralidade do ser humano. Junto a isso, pensamos na ética como elemento indispensável para a formação dos sujeitos éticos. Adotou-se como linha teórica, autores que defende um modelo de formação integral, tendo a ética como indispensável para o processo formativo. O texto é de caráter bibliográfico, pautado na abordagem qualitativa. Sua relevância consiste em apontar caminhos que olhem para a educação de forma mais ampla, o que necessariamente implica olhar para o ser humano de forma integral. Diante disso, concluímos que uma educação que visa a formação humana é aquela que tem em seus pressupostos preparar indivíduos para a sociedade e, para tal, não se pode ignorar no seu exercício a ética como elemento fundante, visto que pensar a educação é pensar o ser humano na sua totalidade.

Palavras-chave: Educação; Ética; Formação Humana.

\begin{abstract}
The goal of this text is to discuss the importance of education and ethics as fundamental elements for human formation. We start from the assumption that education is not a simple exercise of transmitting information or content, yet a training process that must take in consideration the integrality of what means being a human. Along with this, we think of ethics as an indispensable element toward the formation of ethical subjects. It was adopted as a theoretical line, authors who defend a comprehensive training model, with ethics as indispensable for the training process. The text is bibliographic in character, based on the qualitative approach. Its relevance consists in pointing out ways that look at education broadly, which necessarily implies looking at the human being in an integral way. Therefore, we conclude that an education that aims at human formation is the one that has in its presuppositions the goal to
\end{abstract}


prepare individuals for society, and for that, ethics cannot be ignored in its exercise, since thinking education is thinking the man in his entirety.

Keywords: Education; Ethic; Human formation.

\section{Introdução}

Uma das verdades mais substanciais a respeito do ser humano é que ele nasce indefeso. Sua sobrevivência depende do amparo, proteção e cuidado de outro ser humano que geralmente já se encontra em uma fase de maturação mais independente. Isso revela uma outra verdade fundamental: diferente do animal, o homem não nasce determinado, pronto e acabado. Seu desenvolvimento como ser humano se dá sempre na relação com o outro por meio de uma interdependência.

Assim, evidencia-se que o caráter biológico, social e cultural se configuram como elementos fundamentais para se compreender o desenvolvimento do ser humano em todas as suas dimensões. Desse modo é importante destacar o homem como um ser social e histórico, seu desenvolvimento se dá na interdependência e no intercâmbio e um dos meios mais eficazes para que esse desenvolvimento aconteça é por meio da educação. Assim, compreendemos que essa educação se inicia no seio familiar e se torna mais propositiva, sistematizada e intencional por meio da escola que hoje se apresenta como um lócus privilegiado para a produção de saberes historicamente construídos.

A educação é própria dos seres humanos, ou como observou Freire (1999, p. 43): "não há educação fora das sociedades humanas e não há homem no vazio". Deste modo, a educação se apresenta como um dos mecanismos mais indispensáveis para o processo da formação humana. Formação essa que por sua vez dura a vida inteira. Isto quer dizer que a formação humana, por meio da educação, é uma tarefa essencialmente permanente que acontece em todas as instâncias da sociedade.

Desde a família, primeiro núcleo social no qual nos relacionamos com o outro, passando por diversas instituições, tais quais, a escola (instituição formal de ensino), as religiões, associações, clubes esportivos, comunidades em que vivemos, entre outros, é que acontecem processos educativos em nossas vidas (ALVES, 2016, p. 2).

Com isso, compreendemos que a educação deve cumprir não apenas uma função individual, mas sobretudo social. A educação é tida como um processo de formação 
humana e deve buscar não apenas transmitir um conjunto de saberes sistematizados, mas deve também se ocupar com a formação integral do ser humano, com o intuito de preparálo para a sociedade. Desta maneira, no processo educativo precisa considerar em suas propostas, um comprometimento com a sociedade como um todo, o que implica uma educação muito mais ampla, com um conhecimento crítico, que busca a integração social, além do entendimento e do engajamento contra as injustiças e desigualdades.

A educação tem sua ação na cognição, no desenvolvimento motor, sensorial, psíquico e social do indivíduo, sendo também seu próprio processo de humanização. Por este motivo, surge a necessidade em ofertála da melhor forma possivel, garantindo qualidade, e de maneira que possibilite e/ou oportunize um convívio cortês e respeitoso entre as pessoas, bem como o favorecimento de seu intelecto. Assim sendo, espera-se que o ser humano tenha capacidade de discernir e viver em comunhão com seu próximo, baseado nas lições e nos valores que estruturam sua vida. (ALVES, 2016, p. 3).

Como se nota, por detrás de todo processo pedagógico existe uma antropologia filosófica, uma visão de homem, e a partir dessa visão é possível delimitar o tipo de formação que se deseja dar, bem como, a compreensão de que tipo de sociedade que se quer construir. Por isso, é urgente e fundamental que a educação não seja tida como a mera transmissão de informações, mas como um processo de formação humana, como bem pontuou Piaget (1998, p. 33): "a educação é, por conseguinte, não apenas uma formação, mas uma condição formadora necessária ao próprio desenvolvimento natural".

É preciso compreender também que o ato educativo acontece para além dos muros da escola. Isto não significa que processo educativo, por extrapolar os limites do espaço escolar, desqualifica a escola como o lócus privilegiado de uma formação mais formal. No entanto, pode-se insistir que o processo não se encerra na escola, uma vez que continua em outros espaços e, principalmente naqueles que têm um peso maior na vida do ser humano. Deste modo,

Estando a educação onde há vida humana, não se limitando às instituições formais de ensino, podemos conferir sua realização nos espaços nãoformais e/ou informais. É fato sua ocorrência nos núcleos não formalizados, que extrapolam a escola, mas que de certa forma vivem a educação, proporcionando também o desenvolvimento dos indivíduos, pois, direta ou indiretamente se ocupam em educar e consequente a isto formam também valores na sociedade (ALVES, 2016, p. 4). 
Com isso, compreende-se uma continuidade no processo educativo que se desenvolve de forma paulatina à medida que o ser humano atua e convive com o outro. Assim, é crucial que as instituições credenciadas para a mediação do conhecimento e dos saberes historicamente elaborados compreendam a dimensão social e humana no processo educativo.

Tendo feito essas observações, o presente trabalho tem como problemática a seguinte questão: como a ética pode contribuir para a formação humana? Para responder a essa problemática elencamos como objetivo principal compreender a educação como um processo de formação humana. Ademais, como objetivo específico buscou-se compreender a ética como elemento fundamental para se estabelecer uma educação que olha o ser humano em sua integralidade. De modo a atender a esses objetivos, o percurso metodológico foi pautado nos pressupostos da abordagem qualitativa, por meio de uma revisão bibliográfica, pois compreendemos que essa permite o aprofundamento e ampliação dos pressupostos teóricos de autores que discutem a temática e o objeto de estudo (LAKATOS; MARCONI, 2003).

Nesse contexto, foi possível constatar que só se pode falar de educação como processo da formação humana quando esta prepara os sujeitos para a vida social. Isso posto, é necessário compreender a educação a partir de uma perspectiva mais ampla, que não se restringe à mera transmissão de conteúdos. Um processo formativo que se diga de qualidade tem a ética como fundamental, visto que essas duas (educação e ética) se entrelaçam e uma não pode acontecer sem a outra.

\section{O que é a educação?}

A história nos apresenta de forma muito clara que a educação sempre ocupou um lugar importante na formação de um povo. Kant (1999, p. 11) nos ajuda nessa compreensão ao dizer que "o homem é a única criatura que precisa ser educada". Desta forma, a educação é compreendida como elemento fundamental para a formação humana. Assim, "a proposição é uma assertiva sobre a educação, e a sua relação com o ser humano é assumida como princípio fundante" (RODRIGUES, 2001, p. 240). Isto torna a educação indispensável para que o ser humano seja constituído, ou, como prossegue Kant (1999, p. 
15), "o homem não pode se tornar um verdadeiro homem senão pela educação. Ele é aquilo que a educação dele faz." Assim, evidencia-se que a formação humana por meio da educação se dá mediante um ato intencional que busca imprimir no ser humano o melhor da humanidade.

É diante do exposto que Saviani (2013, p. 13) compreende que "o trabalho educativo busca 'produzir, direta e intencionalmente, em cada indivíduo singular, a humanidade que é produzida histórica e coletivamente pelo conjunto dos homens'. É daí que se pode pensar na educação como um processo de transformar a criatura biológica em um novo ser, ou seja, em um ser de cultura, em um ser social e esse processo só é possível com a educação, por meio de um ato intencional "imposto de fora sobre uma criatura que deve ser formada como ser humano" (RODRIGUES, 2001, p. 241).

Isto posto, nota-se que a educação é própria dos seres humanos e que tem como propósito a formação humana. Pode-se alegar que todo povo que atinge um certo grau de "desenvolvimento sente-se naturalmente inclinado à prática da educação e esta, por sua vez, pertence essencialmente à comunidade" (JAEGER, 2013, p. 1). Desta feita, ninguém escapa da educação. Em casa, na rua, na igreja ou na escola, de um modo ou de muitos, todos nós somos envolvidos por ela: para aprender, para ensinar, para aprender-ensinar. Para saber, para fazer, para ser ou para conviver, todos os dias misturamos a vida com a educação (BRANDÃO, 2006).

Da família à comunidade, a educação existe difusamente entre as incontáveis práticas dos mistérios do aprender. Primeiro, sem classe de alunos, sem livros e sem professores especialistas, mais adiante com escolas, salas, professores e métodos pedagógicos. (BRANDÃO, 2006). Sendo assim, compreende-se que a vida em sociedade exige um modo de viver que só é possível quando se estabelece uma relação dialógica entre indivíduos e essa só é possível por meio da educação, uma educação que busque a todo momento formar cidadãos éticos. Isto é, uma educação que forma homens e mulheres que se articulam na busca de um comportamento justo na vida pública e um modo responsável de usar os conhecimentos e habilidades no espaço onde a vida acontece, visando sempre o bem comum.

Deste modo, pontua-se que as ações educativas devem ser desempenhadas tendo como finalidade a formação de sujeitos éticos. Acreditamos que, por meio da educação, é 
possível uma formação integral do sujeito-cidadão, o que implica pensarmos na construção da formação humana. É por meio da educação que o homem consegue atingir suas potencialidades e desenvolver de maneira mais intencional valores que lhe ajudem na sua integração em sociedade.

\section{Ética e Educação: algumas considerações}

De acordo com Singer (2018); Vázquez (2018) e Nagel (2011), muito se discute a respeito da diferenciação entre ética e moral sob alegação de que a ética se configura em uma reflexão filosófica sobre a moral, e que a moral, por sua vez, seria os costumes, os hábitos, os comportamentos dos seres humanos, as regras de comportamento adotados pelas comunidades. Porém, do ponto de vista da história da filosofia, a diferença entre ética e moral inexiste, uma vez que a moral é a tradução latina para a palavra grega original ética.

Outra confusão recorrente quando se fala em moral é pensar nela como sendo uma forma de punição, condenação ou restrição da nossa liberdade. O que não passa de um equívoco, pois a moral começa propriamente quando somos livres, quando nenhuma punição é possível, "ela é essa liberdade mesma, quando se julga e se comanda" (COMTESPONVILLE, 2009, p. 17).

Peter Singer (2018) em seu livro Ética Prática chama atenção para outros equívocos que, muitas vezes, se tem a respeito da ética. Dentre esses, o autor assinala para o postulado de que o principal tema da ética é o sexo. Quando se pensa na ética é quase que instintivo associá-la à moralidade sexual, o que de certa maneira tem gerado inúmeras controvérsias, porque a questão da sexualidade continua sendo um tabu para muitas famílias e educadores. Não só isso, Singer (2018, p. 19) argumenta que "em relação ao predomínio dessa noção limitada de moralidade, popularizou-se a opinião de que ela seria um sistema de proibições puritanas e irritantes cuja função básica seria a de impedir as pessoas de se divertirem".

Não obstante, Singer (2018) ainda apresenta outro equívoco que vê a ética como uma boa teoria, mas que não funciona na prática, ou seja, um sistema ideal de grande nobreza na teoria, mas inaproveitável na prática. Assim, é cabível saber que um juízo ético que não é bom na prática se deve ressentir também de um defeito teórico, pois a questão 
fundamental dos juízos éticos é orientar a prática. Em outras palavras, essas duas (teoria e prática) não se separam, quando há esse discurso percebe-se uma inexistência de ambas.

Tendo elencado esses equívocos, cabe então conceituar a noção de ética. Para tal, nos apropriamos do posicionamento de autores como Vázquez (2018), Singer (2018) e Comte-Sponville (2009), por compreenderem que tradicionalmente a ética é tida como uma disciplina da filosofia, conhecida por filosofia moral, que enfrenta, dentre muitas questões, o problema de saber como devemos viver. Não obstante, etimologicamente, a palavra "ética" origina-se do termo grego ethos, que significa "o conjunto de costumes, hábitos e valores de uma determinada sociedade ou cultura" (MARCONDES, 2007).

Seguindo este mesmo raciocínio, Vázquez (2018, p. 23) define a ética como sendo "a teoria ou ciência do comportamento moral dos homens em sociedade". Ou seja, é ciência de uma forma específica de comportamento humano. Quanto à moral, Comte-Sponville (2009, p. 20) compreende que é

O conjunto do que um indivíduo se impõe ou proíbe a si mesmo, não para, antes de mais nada, aumentar sua felicidade ou seu bem-estar próprios, o que não passaria de egoísmo, mas para levar em conta os interesses ou os direitos do outro, mas para não ser um canalha, mas para permanecer fiel a certa ideia da humanidade e de si.

Neste sentido, a moral deve responder sempre à pergunta: o que devo fazer? E não "o que os outros devem fazer", porque a moral só é legítima na primeira pessoa. A não ser que se admita que existe um Deus que é o fundamento da moral. Disto compreende-se que a ética não cria a moral, uma vez que a ética é a ciência do comportamento moral dos homens na sociedade.

Não obstante, a ética e a moral abarcam um campo muito amplo, permeando praticamente todos os ramos do saber. Sua relação com a busca do conhecimento é quase que intercambiáveis, ou, como bem coloca Enkvist (2019, p. 16), "desde Sócrates, saber em que consiste a verdade é a condição para agir de maneira virtuosa, porque o mundo do verdadeiro conhecimento e do ato virtuoso é apenas um, ou, dito com outras palavras, a epistemologia e a ética são duas facetas da mesma coisa".

Assim, a ética, na sua forma mais prática, busca em última instância estudar as relações e o comportamento dos homens em sociedade. A ética está relacionada à ação. Deste modo, tudo o que o ser humano faz tem relação com a ética, inclusive o ato educativo, porque cada vez que o homem age faz suas escolhas éticas e nisso inclui a nossa relação com o outro. 
Pode-se dizer que seu objeto de investigação é o comportamento humano em sociedade, mais especificamente o comportamento moral, sendo este constituído pelas ações humanas. A palavra ética vem do grego ethos que pode ser definido como "modo de ser" ou "caráter" e a partir dela é que aspectos como proteção, guarida, hospitalidade, podem ser estabelecidos (CAMARGO, 2013, p. 81).

Por ser também um ser histórico, o homem se constrói na relação com o outro e nessa relação vai adquirindo as virtudes relativas à ética. Para este processo a escola é crucial, visto que por meio da educação atua, promove e dissemina de maneira explícita as questões éticas, de modo a garantir um ambiente escolar caracterizado pelo respeito, pela verdade e pelo acolhimento ao outro. Não só isso! Considerando que a educação deve se preocupar também com a formação do cidadão, a ética se torna fundamental para este processo, como já salientamos em outros momentos do texto.

Neste sentido, a educação visa à formação do homem integral de modo a prepará-lo para a sociedade. "A ética oferece suporte à educação ao auxiliá-la a responder as questões que a preocupam, por exemplo, que tipo de homem se pretende formar, para que sociedade esta formação deve estar direcionada" (CAMARGO, 2013, p. 81). Assim, é fundamental que esse processo formativo ocorra de maneira clara e rigorosa, assim como ter bem definidos os valores que devem ser adotados, visto que valores, normas e julgamentos morais fazem parte de qualquer sociedade e se constroem na relação com o outro no percurso histórico.

Adere-se aos valores morais por meio da convivência, na relação que se estabelece com o outro. Pelo fato de em algumas situações essas normas de convivência ou valores serem impostas sem necessariamente o consentimento de todos e sem uma reflexão prévia, faz com que a escola, como espaço de reflexão, auxilie os indivíduos na problematização de tais questões de modo a se encontrar sempre os melhores caminhos a serem trilhados.

É por isso que por meio da reflexão ética que se pode julgar as ações, visto que os comportamentos humanos ou a moral não é algo que se constrói de maneira isolada ou arbitrária, mas num esforço conjunto por meio da convivência social. Aquilo que é estabelecido pela sociedade como mecanismos para uma boa convivência deverá passar também pelo crivo do indivíduo. Este, que por sua vez, atribui valor a essas normas que são impostas ou não, afinal é, 
Por meio da moral que o indivíduo as praticará ou não, tudo depende do valor que é dado a esse comportamento. Com isso, cada cultura estabelece os que serão os padrões a serem seguidos e a partir de um já existente novos vão se constituindo (CAMARGO, 2013, p. 83)

Os valores morais carregam consigo uma força considerável, ou seja, eles ditam como deve ser o comportamento do indivíduo dentro da sociedade. Isso não significa que não podem ser desobedecidos. Por isso é necessário que se tenha consciência desses valores. A consciência aqui é definida como sendo "saber de si para consigo" (COMTESPONVILLE, 2009, p. 21). Isto quer dizer que estar em regras com a sociedade não dispensa o indivíduo de estar em regra consigo mesmo, com sua consciência. Ou como bem observou Comte-Sponville (2022, p.19),

Toda moral é relação com outro, só que de si consigo. Agir moralmente é levar em conta os interesses do outro, por certo, mas 'sem que os deuses e os homens saibam', como diz Platão; em outras palavras, sem recompensa nem castigo possível e sem necessitar para tanto de nenhum outro olhar além do seu mesmo.

Está implícito nessa ideia de consciência o direito de escolha, o que de certa maneira possibilita uma responsabilização dos atos. Somente quando se admite que se tem liberdade de opção e de decisão é que se pode responsabilizar alguém pelos seus atos. Em outras palavras, não se pode responsabilizar alguém pelos seus atos quando se elimina da equação o princípio da liberdade. Não obstante, "de modo geral, as escolhas estão envolvidas por valores morais que foram estabelecidos na sociedade em que se insere." (CAMARGO, 2013, p. 83).

Ora, por valor se entende esse reconhecimento ou atribuição que o homem dá à determinada coisa (por exemplo, considerando-as belas, justas ou sagradas), o que nos leva a termos uma atitude favorável para com elas no que se reflete em nossos atos e escolhas. Os valores podem ser entendidos a partir de posturas objetivistas, que alegam que as coisas são valiosas independentemente de as valorizarmos ou não, e as subjetivistas, que consideram as coisas valiosas simplesmente porque as valorizamos. Colocado de outra maneira,

O valor não é propriedade dos objetos em si, mas adquirida graças à sua relação com o homem como ser social. Mas, por sua vez, os objetos podem ter valor somente quando dotados realmente de certas propriedades objetivas (VÁZOUEZ, 2018, p. 141). 
Deste modo, infere-se que os valores se constroem na relação entre objetivo e subjetivo. Não obstante, é na relação entre indivíduos que acontece a construção dos valores, e nisso cada pessoa passa a ser norteada pelos valores que adquire e constrói nessa interação com seu semelhante.

A preocupação atual com os valores se dá pelo fato de as sociedades passarem por inúmeras transformações e, evidentemente, pelo modo como elas se organizam diante do processo de globalização. Lipovetsky (1989), sociólogo francês, define a nossa era como sendo a época do vazio e do efêmero. Nas palavras de Enkvist (2019, p. 29),

Ora, a educação que quer sempre agradar não protege o indivíduo das decepções, mas sim gera jovens vulneráveis e facilmente frustráveis. São tão livres que já se chegou a afirmar que estão sem obrigações nem sanção ou "sem lei". A grande libertação da sociedade tradicional parece não ter trazido consigo a felicidade, mas a ansiedade e a frivolidade.

Diante disso, constata-se que a relativização da moral, em absoluto, pode gerar consequências desastrosas no processo formativo, uma vez que não se poderá estabelecer parâmetros que possam orientar de forma clara esse processo. Deste modo, a moral não pode ser algo que somente a sociedade deve ter, e não necessariamente o cidadão, visto que para o sociólogo Lipovetsky (1989, p. 54) isso seria o mesmo que "desresponsabilizar o cidadão", uma vez que apenas o Estado supostamente tem responsabilidade.

Para Lipovetsky (1989) as normas dadas tanto pelas famílias quanto pela educação não são suficientemente claras para a segurança do indivíduo. Este, por sua vez, por não se apoiar em algo chamado tradição, sente-se ansioso e cansado, pois tem que tomar muitas decisões que, às vezes, o deixa indeciso. Ainda, o sociólogo assinala o consumo como sendo outro problema da nossa era, incluindo as mercadorias, as experiências, as distrações e as emoções. Tudo é caracterizado por não exigir esforço algum, nem qualquer responsabilidade.

É nesse rol em que a escola existe para propiciar e assegurar de maneira respeitosa a transmissão dos valores que são caros à convivência e imprescindíveis para a formação integral do ser humano. É necessário que a escola esteja ciente de que é composta por inúmeras culturas, ou até mesmo que o ser humano é extremamente complexo, o que torna, deste modo, cada escola diferente das demais. A escola deve prezar por aquilo que é mais indispensável: priorizar valores como justiça, bondade, lealdade, respeito, entre 
outros. Deste modo, enfatizamos que no que tange à formação humana tanto a educação quanto a ética são indispensáveis.

\section{O mal-estar da sociedade contemporânea: A ética como elemento indispensável na formação integral do sujeito}

As transformações que ocorrem na sociedade reconfiguram os valores morais. Assim, o modo como as sociedades se organizam, em certa medida, determina sua visão em relação aos valores morais que ela adota e esta realidade afeta diretamente o processo formativo do cidadão, visto que a educação deverá sempre colocar a moral em perspectiva. Com isso, não se quer eliminar o caráter permanente que existe entre a busca do conhecimento e a busca de um viver virtuoso. Como bem observou Enkvist (2019, p. 16),

Desde Sócrates, saber em que consiste a verdade é a condição para agir de maneira virtuosa, porque o mundo do verdadeiro conhecimento e do ato virtuoso é apenas um, ou, dito com outras palavras, a epistemologia e a ética são duas faces da mesma coisa.

No decorrer da história ocorreram muitas mudanças que inverteram a lógica do que foi dito acima. Assim, não mais se manteve essa relação quase que indissociável entre a busca pelo conhecimento com o ato virtuoso. Disso resultou que nossa sociedade passou a ser caracterizada de diversas maneiras: desde: Sociedades líquidas ${ }^{1} ;$ Era do vazio $^{2}$ e Sociedade do self $\beta^{3}$. Em que o ensino de uma ética explícita é visto como doutrinação ou imposição. Mas se a educação for um processo de construção humana, então a ética - que está relacionada à ação e que por meio dela se expressa nas escolhas que se faz, os valores que se adota e o modo como nos relacionamos com o outro - se torna imprescindível no processo da formação.

Na sociedade contemporânea principalmente com os avanços tecnológicos e expansão da comunicação em massa, os valores morais tidos como normativos estão perdendo suas forças, eles passam a priorizar muito mais o indivíduo isoladamente, ou seja, a subjetividade impera neste momento de maneira a romper com os valores até então estabelecidos, e é neste cenário que a educação atua, pois ao mesmo tempo em que necessita transmitir os conhecimentos socialmente construídos, depara-se com a eclosão de novos valores que se modificam rapidamente e interferem no desenvolvimento do indivíduo (CAMARGO, 2013, p. 81).

\footnotetext{
${ }^{1}$ Zygmunt Bauman (2001).

${ }^{2}$ Gilles Lipvestky (1989).

${ }^{3}$ Charles Taylor (2011).
} 
Diante dessa sociedade que se apresenta cada vez mais relativista, individualista, em que os espaços e visões de mundos devem ser compartimentados, os valores são relativizados, uma vez que a subjetividade do indivíduo ganha mais importância do que o pensar coletivo, o que, de certa maneira, agrava e desnorteia o processo educativo e a própria escola. Charles Taylor (2011) observa que mesmo que a sociedade continue se desenvolvendo em outros âmbitos do saber, como na ciência, ainda assim ela experimenta um declínio, como o autor denominou de "mal-estar". Deste modo, Taylor elenca o individualismo como uma das primeiras preocupações. Segundo ele

Nós vivemos em um mundo no qual as pessoas possuem o direito de escolher por si mesmas o próprio modo de vida, de decidir conscientemente quais as convicções abraçar, de determinar o formato de sua vida em uma série de maneiras que seus antepassados não podiam controlar (TAYLOR, 2011, p. 12).

Sendo considerado uma conquista da civilização, os direitos são ou pelo menos devem ser resguardados e defendidos pelos sistemas legais. Assim, as pessoas já não podem mais ser sacrificadas em nome de uma suposta ordem que as transcendem. Evidentemente que para muitos isso não é suficiente, já que os arranjos econômicos, os padrões familiares e as noções tradicionais de hierarquia ainda continuam a tolher nossas liberdades, nos impedindo de sermos nós mesmos. Não obstante, Taylor (2011, p. 12) observa que, apesar disso, muitos de nós somos ambivalentes e que "a liberdade moderna foi ganha por nossa fuga dos antigos horizontes morais. As pessoas costumavam se ver como parte de uma ordem maior." Mas a sociedade contemporânea se desencantou dessa ordem, uma vez que tudo era quase que determinado.

Com isso, as pessoas foram perdendo a sensação de propósito, aquele bem maior que por ele valia a pena morrer. "Tal perda de propósito estava ligada a um estreitamento. As pessoas perderam a visão mais abrangente porque se centraram na vida individual." (TAYLOR, 2011, p. 13). Deste modo, a sociedade foi se tornando mais permissiva, se caracterizando como a geração do "eu" sob a prevalência do "narcisismo". O individualismo tem o seu lado negativo e perturbador, e este lado sombrio é o "centrar-se em si mesmo, que tanto nivela quanto restringe nossa vida, tornando-a mais pobre em significado e menos preocupada com os outros ou com a sociedade" (TAYLOR, 2011, p. 14). 
Decorre do exposto que a escola como tal enfrenta um grande desafio e para atingir seus objetivos no que se refere ao processo formativo, o de não reduzir a educação à mera transmissão de conteúdo, deverá encontrar uma maneira de desenvolver uma educação ética. Neste cenário, a educação deve ser compreendida a partir de uma amplitude maior, ou seja, como uma prática social ao qual o ser humano faz parte. Assim, a relação entre ética e educação se torna imprescindível no processo educativo.

\section{Considerações Finais: formação humana e suas implicações na integralidade do ser humano}

O trabalho teve como objetivo abordar a relação da educação e da ética no processo da formação humana. Ressaltamos que a educação não deve ser concebida como sendo um mero exercício de transmissão de informações, uma vez que essa concepção reduz a educação a um vazio que se estrutura a partir do mero conteudismo.

Evidenciou-se no trabalho que para que ocorra de fato a formação humana, por meio da educação, é necessário que seja pensada na sua relação com a ética, uma vez que esta, como enfatizamos, se configura em um dos elementos mais fundamentais e imprescindíveis para essa formação humana.

Assim, para atendermos ao objetivo proposto, discorremos a respeito da educação e sua importância no processo de formação, compreendendo que ela é própria dos seres humanos e que "todo povo que atinge um certo grau de desenvolvimento sente-se naturalmente inclinado à prática da educação" (JAEGER, 2013, p. 1). Com isso em vista, compreendemos a dimensão social do ser humano para esse processo, uma vez que é também nas relações interpessoais que a formação humana acontece.

Não obstante, buscamos aprofundar o conceito de ética e sua distinção com relação ao significado de moral, mesmo que partindo do pressuposto de que a partir de um ponto de vista da história da filosofia não é recorrente a diferenciação entre esses dois conceitos. $\mathrm{E}$ apoiamo-nos em autores como Vázquez (2018, p. 24), por compreender que "a moral vem do latim mos ou mores, 'costume' ou 'costumes', no sentido de um conjunto de normas ou regras adquiridas por hábito". Deste modo, a moral se refere ao comportamento que o homem adquire nas suas relações. Já a ética, vem do grego ethos, que significa 
analogamente 'modo de ser' ou 'caráter' enquanto forma de vida também adquirida ou conquistada pelo homem. Assim, tanto a moral quanto a ética se configuram num modo de comportamento que não corresponde a uma disposição natural, mas a conquista por hábito.

Frente esse debate, considerou-se ainda a necessidade de se pensar a educação e sua relação com a ética para o processo da formação humana, por entendermos que o homem é por natureza um ser social. Desta maneira ele necessita de outros seres humanos para sua subsistência, pois é dentro do contexto histórico-social que a educação e a ética florescem, auxiliando a reflexão sobre a vida com o objetivo de torná-la melhor. A educação por meio da ética conduz o homem a um aperfeiçoamento do conviver em um processo de valorização do bem comum.

Abordamos ainda a importância da educação escolar, por esta ocupar o lócus privilegiado para articular o processo formativo, concluindo que não se pode pensar em educação e formação humana sem essa instituição. Consideramos ainda que o tipo de educação que se dedica apenas a enxertar conhecimentos prontos, reduzindo o ser humano a uma espécie de computador apto a receber e reproduzir informações de forma automática, não é uma educação que almejamos, muito menos poderá contribuir com a formação humana crítica e ética.

Esse reducionismo massifica o estudante e separa sua inteligência do núcleo afetivo e existencial em que ele está integrado. A todos é ensinado tudo da mesma forma, sem qualquer particularização didática. Para otimizar esse processo de reprodução mecânica, fragmentam-se as disciplinas em subcategorias, dividindo também os professores, que não estabelecem nenhum contato duradouro com os educandos. "A unidade do saber é pulverizada em ilhas temáticas que não formam um arquipélago orgânico" (PINHEIRO, 2016, p. 1).

O resultado dessa educação fragmentada e desconexa é a perda do sentido de completude e ausência de orientação moral e cultural do aluno, que não logra articular o tempo histórico em que vive a partir dos paradigmas de conhecimento que o governam. Entretanto, o objetivo da educação é a integração dos saberes numa unidade global de sentido, assim como a unidade dos conhecimentos com a vida. O ensino interdisciplinar volta-se à reintegração das ciências dispersas, formando um conjunto interdependente de 
saberes articulados e propiciando uma visão do conjunto. "Por exemplo, relaciona-se a História à Literatura, a Geografia à Economia e a Física à Biologia. A partir dessa reunião, o ensino transdisciplinar apresenta o contexto histórico da época, da mentalidade e da cultura em geral" (PINHEIRO, 2016, p. 1).

Deve-se, portanto, no processo educativo, se levar em consideração não somente a dimensão intelectual do ser humano, mas também suas outras dimensões como a moral, a cultural e a espiritual, que dependem da consideração da experiência concreta do educando para a adequada assimilação do conteúdo transmitido. Assim, se faz necessário pensar em se recuperar a dimensão humanista da educação.

A educação personalizada promove a formação moral do educando, considerando as virtudes que atualizam as potências da sua personalidade. Desse modo, supera-se a dimensão apenas intelectual do ensino e se alcança a dimensão vital mais profunda da educação que é a base em que a inteligência se desenvolve. É nessa dimensão, propriamente pedagógica, que a ação educativa se harmoniza num equilíbrio entre moral e intelectual da pessoa em formação. Neste sentido, argumenta Rodrigues (2001, p. 249), "o homem educado é aquele que atingiu a sua maioridade, que se emancipou de todos os que foram seus auxiliares nesse processo formativo".

Diante do exposto, considerou-se de maneira muito precisa que a educação tem como finalidade última a formação humana. Assim, é necessário considerar que existe uma relação quase que indissociável entre a educação e a ética quando se busca a formação dos cidadãos. Com isso, espera-se que a escola, como instituição privilegiada para o processo educativo, ofereça aos seus educandos uma formação mais humana. Assim, é fundamental que o ser humano, por intermédio da educação, seja integrado socialmente para que possa desenvolver-se em todas as suas dimensões.

Partimos do pressuposto de que o ser humano é o único ser que necessita de educação e, por educação, não se pretendeu subscrever ao que é normalmente compreendido, um exercício de transmissão de conteúdo, que consiste em depositar de forma irrefletida um conjunto de informações que nada tem a ver com a existência do aluno. Concluímos, assim, que a ética tem um papel central nesse processo formativo, principalmente em uma sociedade que se vê a cada dia mais pulverizada com ideias que afastam para longe uma formação que se ocupe com uma formação integral. Assim, 
apontamos a importância da ética como elemento indispensável à tarefa da educação. Nisso, encontramos uma confluência entre a educação, ética e formação humana.

\section{Referências Bibliográficas}

ALVES, Janaina Bastos. Educação e a formação humana. In: Encontro Estadual de História, 8, 2016, Feira de Santa, 2016.

ARANHA, M. L. de A. História da Educação. São Paulo: Moderna, 1996

BAUMAN, Zygmunt. Modernidade Líquida. Rio de janeiro: Jorge Zahar, 2001.

BRANDÃO, Carlos Rodrigues. O que é educação. São Paulo: Brasiliense, 2006.

CAMARGO, Marcela Pedroso de. Ética e educação: reflexões sobre os valores morais. Revista filosofia capital, v. 8, 15 ed., 2013.

COMTE-SPONVILLE, André. Apresentação da filosofia. São Paulo: Martins Fontes, 2009.

ENKVIST, Inger. Educação: guia para perplexos. Campinas, SP: CEDET, 2019.

FREIRE, Paulo. Educação como prática da liberdade. Rio de Janeiro, paz e Terra, 1999.

JAEGER, Werner Wilhelm. Paideia: a formação do homem grego. São Paulo: Editora WMF Martins Fontes, 2013.

LIPOVETSKY, Gilles. A era do vazio: ensaio sobre o individualismo contemporâneo. Lisboa: Relógio D’Água Editores Ltda, 1989.

MARCONI, M. A; LAKATOS, E.M. Fundamentos de metodologia científica. 5 ed. São Paulo: Atlas S.A, 2003.

MARCONDES, Danilo. Textos básicos de ética: de Platão a Foucault. Rio de Janeiro: Zahar, 2007.

NAGEL, Thomas. Uma breve introdução à filosofia. São Paulo: Editora WMF Martins Fontes, 2011.

PIAGET, Jean. Para onde vai a educação? Tradução: Ivete Braga. 14 ed. Rio De Janeiro: José Olimpio, 1998.

PINHEIRO, Victor Sales. A indelegável educação dos filhos. Publicado no Jornal O Liberal de 26. junho.2016. Disponível em: <https://www.dialetico.com.br/2018/10/11/a-indelegaveleducacao-dos-filhos/>. Acesso em: 22 out. 2020.

KANT, Immanuel. Sobre a pedagogia. Piracicaba: Editora Unimep, 1999. 
RODRIGUES, Neidson. Educação: da formação humana à construção do sujeito ético. Educação e Sociedade, ano XXII, n. 76, out., 2001.

SAVIANI, Dermeval. Pedagogia histórico-crítica: primeiras aproximações. Campinas, SP: Autores Associados, 2013.

SINGER, Peter. Ética prática. São Paulo: Martins Fontes, 2018.

TAYLOR, Charles. A ética da autenticidade. São Paulo: É realizações Editora, 2011.

VÁZQUEZ, Sánchez Adolfo. Ética. Rio de Janeiro: Civilização Brasileira, 2018.

\footnotetext{
' Possui graduação em Filosofia pela Claretiano Centro Universitário, pós-graduação latu sensu em Filosofia e ensino de Filosofia e graduação em Teologia pela Faculdades Batista do Paraná (2016). Mestrando e bolsista CAPES pelo Programa de Pós-graduação em Educação da Universidade Estadual de Londrina.

ii Possui Graduação em Pedagogia pela Universidade Federal de Rondônia. Mestranda e bolsista CAPES pelo Programa de Pós-graduação em Educação da Universidade Estadual de Londrina.

iii Possui graduação em Pedagogia e Especialização em Sociologia da Educação pela Universidade Estadual de Londrina, Mestrado em Educação pela Universidade Estadual de Ponta Grossa. Doutorado em Educação pela Pontifícia Universidade Católica de São Paulo. Pós Doutora em Educação pela Universidade Federal Fluminense (Bolsista PNPD/CAPES). É professora do Cursos de Pedagogia, do Curso de Especialização em Docência na Educação Superior e do Programa de Pós-graduação em educação da Universidade Estadual de Londrina.
} 